\section{A COMPARISON OF MACROSCOPIC LIPID CONTENT WITHIN PORCINE PULMONARY AND AORTIC VALVES}

\section{Implications for bioprosthetic valves}

Lipid droplets have been demonstrated within both explanted porcine bioprostheses and normal porcine aortic valves. Because of the increasing interest in pulmonary valves as an allograft or xenograft aortic valve substitute, we examined the incidence and distribution of such lipid deposits in $\mathbf{5 0}$ porcine aortic valves and $\mathbf{5 0}$ matched porcine pulmonary valves. All 300 cusps were removed with surgical scissors and, under a dissecting microscope, the ventricularis layer was removed to expose the spongiosal layer. Macroscopic extracellular lipid droplets were exposed. The position and amount of the visible unstained droplets were analyzed by means of a dissecting microscope with an eyepiece grid and stereology point-counting techniques to provide an area-density average spatial probability map for each cusp. Only $8 \%$ of porcine aortic valves were free of lipid, with the distribution of the lipids being $52 \% \pm 14 \%$ right coronary cusp, $90 \% \pm 8 \%$ left coronary cusp, and $68 \% \pm 13 \%$ noncoronary cusp. Of the pulmonary valves, $60 \%$ were free of lipid, with the incidence of lipids being $26 \% \pm 12 \%$ left cusp, $6 \% \pm 7 \%$ right cusp, and $12 \% \pm 9 \%$ anterior cusp. Subsequently, lipid cluster samples underwent thin-layer chromatography, which showed them to be phospholipids, oleic acid (fatty acid), triglycerides, and unesterified cholesterol. One primary mode of bioprosthetic valve failure is leaflet calcification. The similarity of distribution within the spongiosal layer between leaflet calcification and intrinsic cusp lipids suggests that the observed lipids might act as a nucleation site for calcification. The substantially lower incidence of lipid in pulmonary valves therefore may represent a potential benefit when these valves are considered for use as aortic valve replacements. (J THORAC CARDIOVASC SuRG 1995;110:1756-61)

J. Dunmore-Buyze, ${ }^{\mathrm{a}, \mathrm{c}}$ Derek R. Boughner, MD, $\mathrm{PhD},{ }^{\mathrm{a}, \mathrm{c}, \mathrm{d}}$

Nick Macris, BSc, ${ }^{\mathrm{a}, \mathrm{b}}$ and Ivan Vesely, $\mathrm{PhD},{ }^{\mathrm{a}, \mathrm{b}}$ London, Ontario, Canada imited durability is a primary disadvantage of bioprosthetic heart valves. For example, a clinical follow-up study by Bortolotti and colleagues ${ }^{1}$ showed only $40 \%$ of glutaraldehyde-treated porcine aortic valves to be free from primary tissue failure at

From The John P. Robarts Research Institute, ${ }^{a}$ and The Departments of Electrical Engineering, ${ }^{b}$ Medical Biophysics, ${ }^{c}$ and Medicine, ${ }^{d}$ University of Western Ontario, London, Ontario, Canada.

Supported by a grant-inmaid from the Heart \& Stroke Foundation of Ontario. Dr. Vesely is a Research Scholar of the Foundation and Dr. Boughner is a Career Investigator.

Received for publication Feb. 7, 1995.

Accepted for publication May 9, 1995.

Address for reprints: D. R. Boughner, MD, PhD, University Hospital, P.O. Box 5339, 339 Windermere Rd., London, Ontario, Canada N6A 5A5.

Copyright $@ 1995$ by Mosby-Year Book, Inc.

$0022-5223 / 95 \$ 5.00+0 \quad \mathbf{1 2 / 1 / 6 6 2 2 1}$
15 years. A similar large study by Magilligan and associates $^{2}$ reported comparable results.

Bioprosthetic valve failure is structural in nature, involving tissue calcification and tissue rupture. Numerous anticalcification agents are being introduced into the tissue-preparation process, yet the causes of the problem remain uncertain. ${ }^{3-6}$ The specific site of calcium deposition is variable, but deposition has been widely reported to occur in the basal region of the cusps, ${ }^{7-11}$ initially intrinsic, deep within the cusp, and later rupturing outward toward the surface. A reasonable analogy might be the pattern of calcification within vascular atherosclerotic plaques. In that situation, calcium is laid down within the neointima and later may rupture through to the plaque surface, with a strong association suggested between lipids and the calcification process. ${ }^{12,13} \mathrm{We}$ have been considering the possibility of a similar association in prosthetic heart valves, and in a recent 


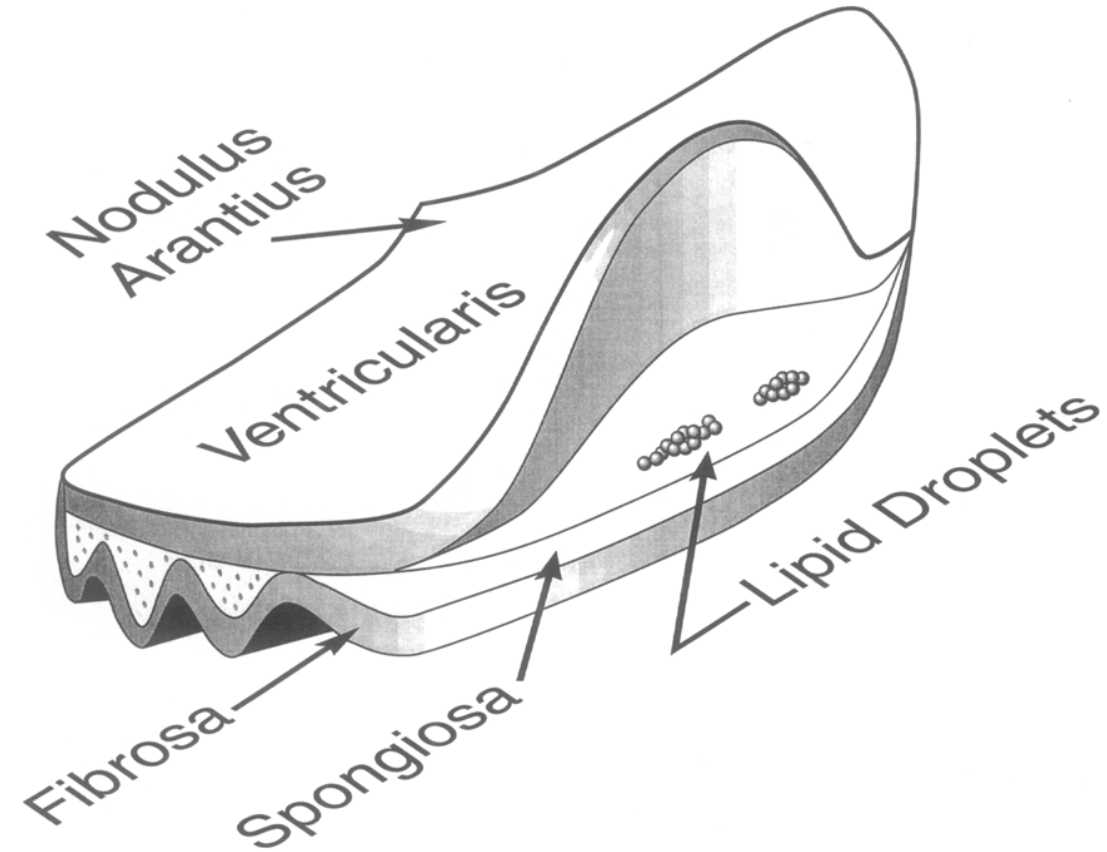

Fig. 1. Schematic diagram representing the lipid clusters found within the spongiosal layer during the dissection of the valve cusps. The ventricularis was grasped with forceps and carefully peeled back to reveal the lipid clusters.

study we described macroscopic lipid deposits within the spongiosal layer of $92 \%$ of porcine aortic valves from the abattoir. ${ }^{14}$ Most of the lipids were located in the basal region of the cusps within the spongiosal layer.

The pulmonary valve has received little attention as a potential source of bioprosthetic tissue, except as an autograft as first described by Ross ${ }^{15}$ in 1962 . The long-term results with that procedure have been extremely good, and similar favorable results were recently reported by others. ${ }^{16-18}$ In this pulmonaryto-aortic autograft, tissue degradation and calcification do not appear to be a problem. ${ }^{18-20}$ Direct mechanical comparisons between porcine pulmonary valves and porcine aortic valves indicate that these valves have nearly identical mechanical properties. ${ }^{21,22}$ Although use of the porcine pulmonary valve as a replacement device has been suggested, its only described advantage has been its structural characteristics; the muscular shelf present in the porcine aortic valve right coronary cusp is not a feature of the pulmonary valve, and the latter therefore might have better hemodynamics. The possibility of other positive structural features was therefore of interest. Because normal human pulmonary valves behave differently from aortic valves over the long term-they do not thicken, calcify, or sclerose like aortic valves-we believed that a macroscopic examination of the material was appropriate and might lend further weight to the argument for considering the porcine pulmonary valve as a potential bioprosthetic device.

\section{Methods}

Fifty whole porcine hearts were obtained from the abattoir and transported to the laboratory on ice slush. Both the aortic and pulmonary valves were excised, and the cusps were removed and labeled according to their anatomic position. The excised cusps were then placed on the stage of a dissecting microscope, and the ventricularis was gently dissected free from the fibrosa along the spongiosal layer. Throughout the dissection procedure, the tissue was kept moist with saline solution.

Macroscopic lipid deposits were easily visualized in the spongiosal layer when present (Fig. 1), and their distribution was quantified with a stereologic point counting technique. ${ }^{14}$ The dissected valve cusp was placed on a piece of celluloid divided into 144 sectors $(12 \times 12)$, and each sector was examined for lipids at a high magnification. An eyepiece with a $10 \times 10$ grid, sized to fit exactly into one of the 144 sectors, was used to view the valve cusps. The presence or absence of a lipid cluster under a stereologic grid point was determined. For the data to be 

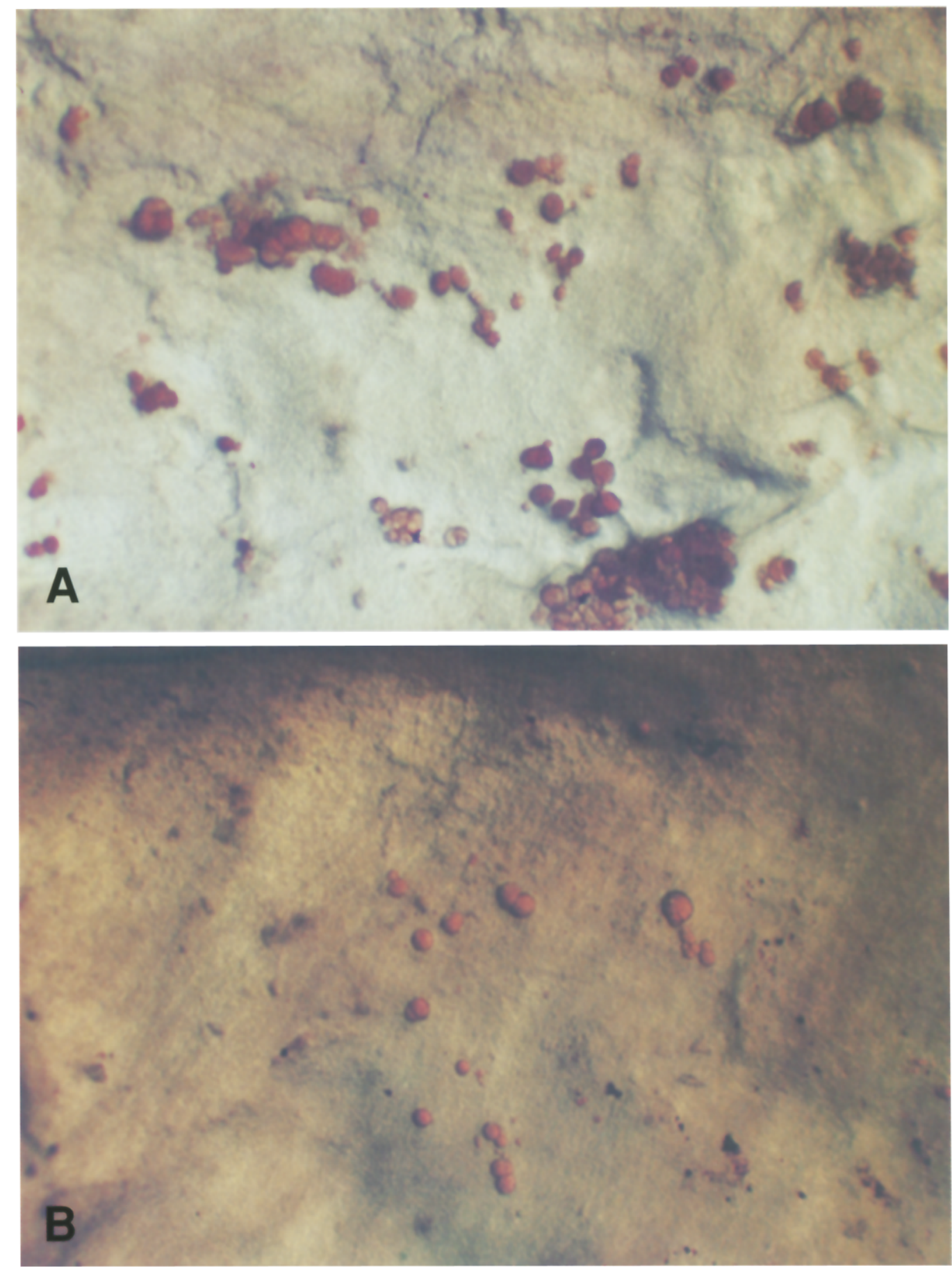

Fig. 2. Low-power light micrograph of fresh tissue stained with $0.1 \%$ oil red $\mathrm{O}$, showing the presence of lipid clusters within the spongiosal layers of (A) aortic and (B) pulmonary valve cusps. The lipid can be identified by staining with oil red $O$.

interpreted statistically, the area data was converted to binary form. "Lipid present" was given a value of $I$ and "lipid absent" was assigned a value of 0 . We then used a calculation to yield a confidence interval for a population proportion. We selected a confidence interval of $95 \% .^{23}$ Regional densities of lipid occurrence were calculated, and frequency of lipid occurrence in a particular region was expressed as a density map image. The density of any 

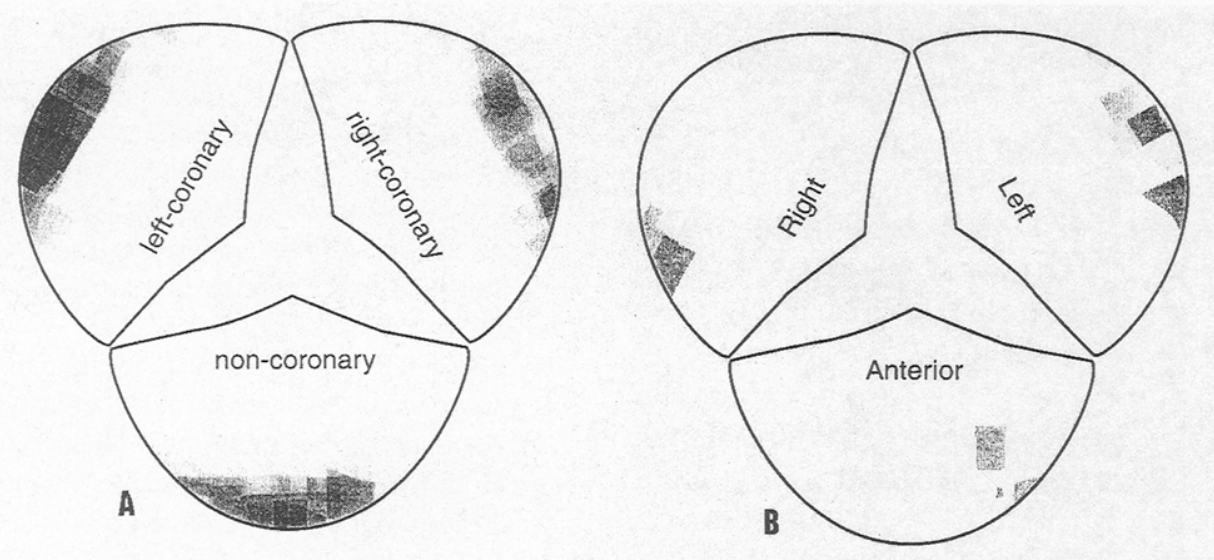

Fig. 3. Mean distribution maps showing the density of lipid clusters found within the 150 cusps of 50 porcine aortic and pulmonary valves. The density, or darkness, of the valve cusp represents the incidence of lipid occurring in that region. Black represents $100 \%$ incidence and white represents $0 \%$. A; aortic valve; B, pulmonary valve.

region on the image was a measure of the frequency of lipid occurrence in that region. Black represented $100 \%$ occurrence and white represented $0 \%$. These density map images of lipid distribution for the 150 aortic and 150 pulmonary cusps were then averaged for each of the three cusps.

After the initial analysis, lipid clusters were excised from the cusps and thin-layer chromatography was performed to establish the nature of the lipid material. Additionally, to verify the lipid nature of the material, oil red $O$ stain was used on frozen sections and whole cusps (bulk staining) to identify the presence of lipid droplets. ${ }^{24}$

\section{Results}

The oil Red $O$ staining of histologic samples confirmed that the droplets present in the spongiosal layer of the valve cusps were indeed lipid material (Fig. 2). Thin-layer chromatography determined these lipids to be predominantly phospholipids, oleic acid (fatty acid), triglycerides, and some unesterified cholesterol. This pattern held true for the droplets observed in both the aortic and pulmonary valves.

On examining the percentage of aortic cusps containing the macroscopic lipid deposits, we found again that $92 \% \pm 18 \%$ of the porcine aortic valves contained lipids. The most commonly involved cusp was the left coronary, with $90 \% \pm 8 \%$ of the cusps likely to contain lipid. The least involved was the right coronary cusp, with lipids seen in $52 \% \pm 14 \%$. In contrast, only $40 \% \pm 14 \%$ of pulmonary valves contained lipids, with the left cusp having the greatest involvement at $26 \% \pm 12 \%$ and the right cusp being the least commonly involved at $6 \% \pm 7 \%$. It was therefore clear that the pulmonary valves were substantially less likely to contain lipids and that the lipid content in any given porcine pulmonary valve was substantially less than for porcine aortic valves.

Average spatial density maps for the six cusps were created ( $n=50$ for each cusp) from the probability density maps, and the predominant site for lipid distribution was shown to be in the basal region (Fig. 3). There was no indication of the lipids extending into the belly of the cusp or along the free edge.

\section{Discussion}

In explanted porcine aortic bioprostheses, Thubrikar, Deck, and Aouad ${ }^{25}$ showed calcification within the spongiosal layer in the basal region of the cusps corresponding to the region of lipid deposition that we observed in both aortic and pulmonary valves. We found no lipids extending into the belly of the cusp, and this region rarely becomes calcified. By comparison, lipids are a prevalent feature in vascular atherosclerosis and are often associated with calcified plaques. ${ }^{12}$ Indeed, phospholipids are reported to be an important component in the formation of the phospholipid-calcium-phosphate complexes that act as the nucleation sites for calcification. ${ }^{26}$ No single explanation for bioprosthesis calcification is likely to exist. Although our study did not include an assessment of cell-bound lipids, the presence of endogenous macroscopic lipid deposits 
within porcine aortic valve cusps used for valve manufacture may be a factor worth considering.

Our findings suggest that the lipids reported by Ferrans and coworkers ${ }^{26}$ in explanted aortic bioprostheses may have been endogenous; that is, implanted when the valve was inserted rather than subsequently accumulated from the blood, as they implied. If a firm relationship can eventually be established between these lipids and the calcification process, we speculate that lipid extraction during the preparation process of bioprosthetic materials or the avoidance of valves with high lipid concentrations might be an appropriate strategy. In that circumstance, the pulmonary valve has a demonstrable advantage. In addition, if the lower incidence of lipid deposition is true for human valves, then the cryopreserved human pulmonary valve might be considered as a suitable homograft.

We thank Cindy Sawyez and Dr. Murray Huff for their advice and technical assistance.

\section{REFERENCES}

1. Bortolotti U, Milano A, Mazzucco A, Valfre C, Talenti E, Guerra F. Results of reoperation for primary tissue failure of porcine bioprostheses. J Thorac Cardiovasc Surg 1985;90:564-9.

2. Magilligan DJ Jr, Lewin W, Stein P, Alan M. The porcine bioprosthetic heart valve: experience at 15 years. Ann Thorac Surg 1989;48:324-30.

3. Golomb G, Dixon M, Smith MS, Schoen FJ, Levy RJ. Controlled-release drug delivery of diphosphonates to inhibit bioprosthetic heart valve calcification: release rate modulation with silicone matrices via drug solubility. J Pharm Sci 1987;76:271-6.

4. Grimm M, Eybl E, Grabenwoger M, Greismacher A, Losert U, Bock P. Biocompatibility of aldehyde-fixed bovine pericardium. I THORAC CARDIOVASC SURG 1991;102:195-201.

5. Girardot JM, Gott JP, Guyton RA. A novel technology inhibits calcification of bioprosthetic heart valves: a Shee pilot study. Trans Soc Biomat 1991;14:60.

6. Levy RJ, Schoen FJ, Levy JT, Flowers WB, Staelin ST. Initiation of mineralization in bioprosthetic heart valves: studies of alkaline phosphatase activity and its inhibition by $\mathrm{A} 1 \mathrm{C} 13$ or $\mathrm{FeC13}$ preincubation. J Biomed Mater Res 1991;25:905-35.

7. Stein PD, Kemp SR, Riddle JM, Lee MW, Lewis JW, Magilligan DJ. Relation of calcification to torn leaflets of spontaneously degenerated porcine bioprosthetic valves. Ann Thorac Surg 1985;40:175-80.

8. Ishihara T, Ferrans VJ, Boyce SW, Jones M, Roberts WC. Structure and classification of cuspal tears and perforations in porcine bioprosthetic cardiac valves implanted in patients. Am J Cardiol 1981;48: 665-78.

9. Pomar JL, Bosch X, Chaitman BR, Pelletier C, Grodin CM. Late tears in leaflets of porcine bioprostheses in adults. Ann Thorac Surg 1984;37:78-83.

10. Grabenwoger M, Grimm M, Eybl E, Kadletz M. New aspects of the degeneration of bioprosthetic heart valves after long-term implantation. J THORAC CARDIOVASC SuRG 1992;104:14-21.

11. Gallo I, Nistal E, Arbe E, Artinano E. Comparative study of primary tissue failure between porcine (Hancock and Carpentier-Edwards) and bovine pericardial (Ionescu-Shiley) bioprostheses in the aortic position at five- to nine-year follow-up. Am J Cardiol 1988;61: 812-6.

12. Kruth HS. Localization of unesterified cholesterol in human atherosclerotic lesions. Am J Pathol 1984;114: 201-8.

13. Mitchison MJ, Hothersall DC, Brooks P, De Burbure $\mathrm{CY}$. The distribution of ceroid in human atherosclerosis. J Pathol 1985;145:177-83.

14. Vesely I, Macris N, Dunmore J, Boughner DR. The distribution and morphology of aortic valve cusp lipids. J Heart Valve Dis 1994;3:451-6.

15. Ross DN. Homograft replacement of the aortic valve. Lancet 1962;2:487.

16. Gerosa G, Ross DN, Brucke PE, et al. Aortic valve replacement with pulmonary homografts: early experiences. J Thorac Cardiovasc Surg 1994;107:42437.

17. Gonzalez-Lavin I, Robles A, Graf D. Morbidity following the Ross operation. J Cardiac Surg 1988; 3(Suppl):306-8.

18. Kouchoukos MP, Davila-Rokan VG, Spray TL, Murphy SF, Perrillo JB. Replacement of the aortic root with a pulmonary autograft in children and young adults with aortic valve disease. N Engl J Med 1994; 330:1-6.

19. Elkins R. Pulmonary autograft-the optimal substitute for the aortic valve. N Engl J Med 1994;330:5960.

20. Gorczynski A, Trenkner M, Anisimowicz L, et al. Biomechanics of the pulmonary autograft in the aortic position. Thorax 1982;37:535-9.

21. David H, Boughner D, Vesely I, Gerosa G. The pulmonary valve: is it mechanically suitable for use as an aortic valve replacement. ASAIO J 1994;40:206-12.

22. Leeson-Dietrich J, Boughner D, Vesely I. Porcine pulmonary and aortic valves: a comparison of their tensile viscoelastic properties at physiological strain rates. J Heart Valve Dis 1995;4:88-94.

23. Mason RD. Introduction to sampling. In: Fetter RB, ed. Statistical techniques in business and economics. Homewood, Illinois: Richard D Irwin 1982:323-5.

24. Kruth HS, Fry DL. Histochemical detection and differentiation of free and esterified cholesterol in 
swine atherosclerosis using filipin. Exp Mol Pathol 1984;40:288-94.

25. Thubrikar MJ, Deck JD, Aouad DUM. Role of mechanical stress in calcification of aortic bioprosthetic valves. J Thorac Cardiovasc Surg 1983;86: 115-25.
25. Boyan BD, Schwartz Z, Swain LD, et al. Role of lipids in calcification of cartilage. Anat Rec 1989;224:211-9.

26. Ferrans VJ, Spray TL, Billingham ME. Structural changes in glutaraldehyde-treated porcine heterografts used as substitute cardiac valves. Am J Cardiol 1978;41:1159-83. 